\title{
CARDIOVASCULAR EFFECTS OF ORAL ANTIVIRAL TREATMENT FOR NON-CARDIAC HCV PATIENTS
}

\author{
By \\ Sameh R H Allam*, Gamal M M Soliman**, Ashraf A Sayed ***, \\ Ahmed A Mahdy*, Mahmoud M Aboelhagag* \\ *Department of Cardiology, **Department of Tropical Medicine، ***Department of \\ Clinical Pathology \\ Faculty of Medicine, AL-Azhar University (Cairo)
}

\begin{abstract}
Background: The prevalence of hepatitis C virus (HCV) in Egypt is quite high, and the combined oral direct-acting antiviral agents (DAAs) may have impressive results.

Objectives: To assess the cardiovascular effects of oral antiviral treatment in non-cardiac HCV patients.

Paitents and Methods: The study enrolled 100 patients with positive HCV who were enrolled for the new oral antiviral therapy in the form of Sofosbuvir and dclatsavir with or without ribavirin for 3 or 6 months. All patients on our study were subjected to follow up pre-and post-oral antiviral course, and the end point of the study was the development of a major cardiovascular event, e.g. congestive heart failure, echocardiographic evidence of left ventricular dysfunction, occurrence of significant arrhythmias, or acute coronary syndrome. The following parameters were accomplished: medical history and clinical examination, electrocardiogram, Echo-Doppler study, and laboratory investigations.

Results: No significant differences were found between the patients regarding demographic criteria. None of the patients had developed any major cardiac event. No significant changes were observed regarding ST segment and $\mathrm{T}$ wave abnormalities, arrhythmias, or QT interval. None of patients developed echocardiographic regional wall motion abnormalities at baseline or at study end. Systolic function parameters showed minute non-significant changes over study visits. Diastolic function parameters showed non-significant changes between baseline and post oral antiviral course visit.
\end{abstract}

Conclusion: The DAAs used in combination regimen didn't significantly affect the cardiovascular system.

Key words: Hepatitis C virus, oral direct antiviral agents, echocardiography.

\section{INTRODUCTION}

Hepatitis $\mathrm{C}$ virus(HCV) is a significant public health problem and the leading cause of liver transplantation and hepatocellular carcinoma (Moyer, 2013). More recent surveillance data suggest that $\mathrm{HCV}$ infection has increased to 5.2 million people in the U.S. (Chak et al. 2015).

Sofosbuvir represents the first key step towards the new era in the management of chronic hepatitis $\mathrm{C}$, since it is the first approved directly acting antiviral agents with excellent tolerability and favorable pharmacokinetic profile, limited potential 
for drug interactions, potent antiviral activity and high genetic barrier against all HCV genotypes. Sofosbuvir has recently become commercially available in combination with ribavirin, achieving high sustained virologic response (SVR) rates after 12-24 weeks of therapy (Keating, 2014 and Pawlotsky, 2014).

On the other hand, oral antiviral treatment for $\mathrm{HCV}$ patients is known to induce cardiac adverse effects, three cases of severe bradyarrhythmia that occurred during treatment with Sofosbuvir plus Daclatasvir, Simeprevir, or Ribavirin occurred among 415 patients treated (Fontaine et al. 2015). Recent reports had drawn the attention to the possible cardiotoxic effect of Sofosbuvir when combined with amiodarone. Occurrence of syncopal attacks was reported in two cases few days after administration of Sofosbuvir (Lashen and Sanhoury. 2016).

Svere pulomary hypertension was newly discovered or exacerbated after using sofosbuvir (Renard et al, 2016).

The present work aimed to assess the cardiovascular effects of oral antiviral treatment in non-cardiac HCV patients.

\section{PATIENTS AND METHODS}

\section{I- Patients:}

Inclusion criteria: This study was carried out on 100 Egyptian cases, who had chronic HCV infection. They attended at Health Insurance clinic in the Luxor governorate during the period from July 1st 2017 to February 28th 2018 they were candidated for treatment by oral antiviral for a period 3 or 6 months.

\section{Exclusion criteria:}

1- Decompensated liver cirrhosis (ascites, encephalopathy and bleeding varices).

2- Auto-immune hepatitis.

3- Chronic hepatitis B.

4- Combined chronic hepatitis $\mathrm{B}$ and $\mathrm{C}$.

5- Patients with uncontrolled psychiatric disorders.

6- Cardiac disease (cardiomyopathy, arrhythmias, ischemia, myocarditis and valvular heart diseases).

7- Advanced renal impairment.

8- Uncontrolled thyroid dysfunction.

9- Poorly echogenic patients.

\section{II- Methods:}

All patients provided written informed consent. All patients included in the study were subjected to the following:

I- Full history taking which included name, age, sex, occupation, residence, shortness of breath, cough, hemoptysis, palpitation, chest pain, and paroxysmal nocturnal dyspnea.

II- Clinical examination including determination of blood pressure, pulse, jugular venous pressure, pallor, jaundice, cyanosis, ascites, edema of the lower limbs, S3, S4 and any detected murmurs.

\section{III- Laboratory investigations:}

a- Liver function tests: SGOT, SGPT, serum bilirubin, serum albumin, alkaline phosphatase and PT.

b- Serum Creatinine and serum urea.

c- Blood glucose (fasting and postprandial).

d- Complete blood picture. 
e- Viral markers specially for HBV, HCV

(Screened by ELIZA technique).

\section{f- TSH.}

IV- Twelve lead ECG: Standard 12 lead ECG was recorded pre-and post-oral antiviral course to document the presence of significant ST changes suggestive of ischemic heart disease with assessment of rhythm, QT/ QTc, PR interval, P wave size, QRS duration and axis and voltage, abnormal Q, T and U waves.

V-Echo-Doppler study: Full 2-D, Mmode, Doppler and color flow mapping echocardiography study (by Phillips HD7 XE machine, 2-4probe) was done pre-and post-oral antiviral course.

\section{D and M-mode dimensions:}

- Left ventricular end diastolic diameter (LVEDD).

- Left ventricular end systolic diameter (LVESD).

- Inter-ventricular septum thickness (IVS).

- Posterior wall thickness (PWT).

- Left atrial and aortic root diameters

- Right ventricle internal dimensions.

Left ventricular systolic function (Mitchell et al, 2018):

- Ejection fraction (EF)\% by M-mode in parasternal short axis view at level of papillary muscle guided by $2 \mathrm{D}$ and long axis parasternal at level mitral valve leaflets tips or apical four chambers(A4C) by (modified Simpson's single plane method).

Left ventricular diastolic function assessed by (Mitchell et al, 2018):
- E/A ratio and tissue Doppler study (evelocity $\& \mathrm{E} / \mathrm{e}$ ).

- Isovolumeteric relaxation time (IVRT).

- Deceleration time (DT).

Right ventricular (RV) function (Rudski et al, 2010):

- RV function both systolic and diastolic by myocardial performance index (MPI).

- RV systolic function by TDI (systolic signal of the lateral tricuspid valve-TVannulus) and tricuspid annular plane systolic excursion (TAPSE).

- RV pressure using tricuspid regurgitations (TR) jet and the RV outflow (RVOT) pattern i.e. parabolic or triangular.

\section{Pulmonary hemodynamics:}

- Pulmonary artery systolic pressure by modified Bernoulli equation from peak TR jet and mean right atrial pressure (Rudski et al, 2010).

- Pulmonary vascular resistance (PVR) estimation by the following equation:

$\{(\mathrm{TRV}) / \mathrm{VTI}-\mathrm{RVOT}\} \times 10+0.16$ (Abbas et al. 2013).

(Where TRV, TR velocity. VTI-RVOT, right ventricular outflow tract velocity time integral).

\section{Statistical analysis:}

All results were obtained pre and post oral antiviral course and statistically analyzed using t-test. $\mathrm{P}$ value $\leq 0.05$ were considered significant. 


\section{RESULTS}

\section{Baseline Characteristics (Table 1):}

Patient's baseline demographics are shown in (Table 1). The mean age of the recruited patients was $46.2 \pm 12.0$ years. The most frequent age group is from 3540 years presenting $23 \%$, followed by the age group (30-35 years) presenting $18 \%$. It is followed by the age group (45-50 years) presenting $13 \%$. Then it is followed by the age groups (40-45 years) and (65-70 years), each presenting $12 \%$. This is followed by age groups 50-55, 55-
60 and 60-65 years representing 6\%, 8\% and $7 \%$ respectively. The least frequent age group is from 70-75 years representing only $1 \%$. The normal curve reveals that age distribution does not follow the normal distribution as the data are skewed to the left.

Forty-eight were males (48\%) and 52 females $(52 \%)$. No statistical significant difference was noted as regard patient's gender $(\mathrm{p}$-value $=0.16)$.

Table (1): Baseline demographics in the studied group

\begin{tabular}{|l|c|}
\hline Baseline characteristic & $\mathrm{N}=100$ \\
\hline Age & $46.2 \pm 12.0$ \\
\hline Gender (Male) & $48 \%$ \\
\hline Diabetes & $28 \%$ \\
\hline Hypertension & $43 \%$ \\
\hline Smoking & $38 \%$ \\
\hline Family history of cardiac disease & $23 \%$ \\
\hline Treatment regimen & $17 \%$ \\
3 Drugs for 3 months & $2 \%$ \\
3 Drugs for 6 months & $78 \%$ \\
2 Drugs for 3 months & $3 \%$ \\
2 Drugs for 3 months & \\
\hline
\end{tabular}

The most prevalent risk factors were hypertension (HTN) in 43 patients $(43 \%)$, diabetes mellitus in 28 patients $(28 \%)$, smoking in 38 patients $(38 \%)$, and positive family history of cardiac disease in 23 patients $(23 \%)$.

According to the treatment regimen, the patients enrolled in this study were distributed into 4 groups as the following (Figure 1):

- Group 1: 3 Drugs for 3 months (sofosbuvir, daclatasvir and ribavirin).
- Group 2: 3 Drugs for 6 months (sofosbuvir, daclatasvir and ribavirin).

- Group 3: 2 Drugs for 3 months (sofosbuvir and daclatasvir).

- Group 4: 2 Drugs for 6 months (sofosbuvir and daclatasvir).

No significance difference between regimen groups when compared by repeated measures ANOVA (pvalue $=0.43$ ). 


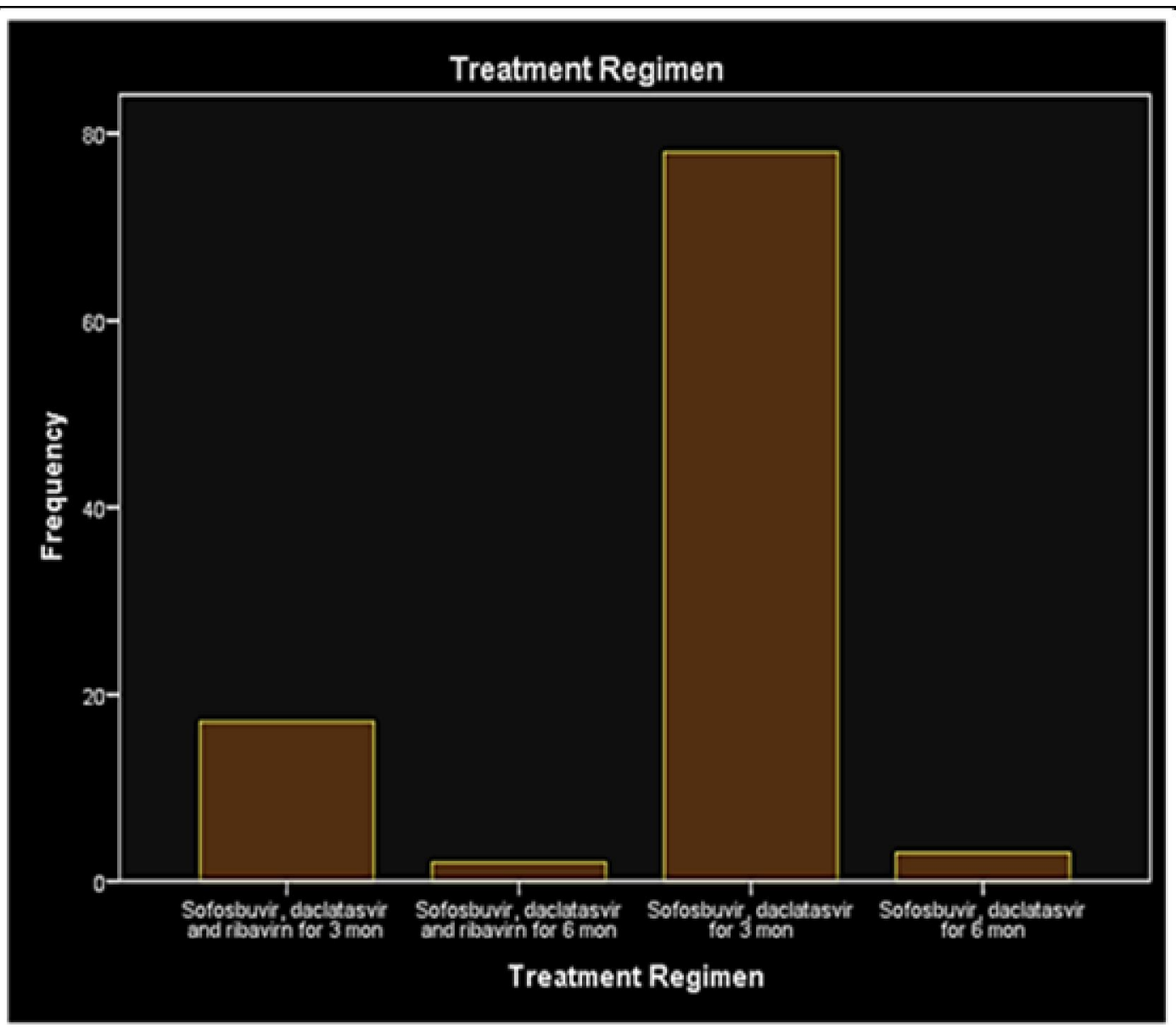

Figure (1): Frequency of patients among groups regimens

In the present study, baseline clinical examination was done as regard shortness of breath, cough, palpitation and chest pain and then reassessed by the end of treatment .

As regard blood pressure, systolic blood pressure showed statistically significant difference with p-value 0.00, however this difference was clinically insignificant $(3 \mathrm{mmHg})$, while diastolic blood pressure showed no statistically significant difference after treatment when compared to their values before treatment $\{78.30 \pm 7.66$ vs $78.90 \pm 9.31 \quad \mathrm{mmHg}$ respectively\} (Table 2 ).

Table (2): Blood pressure before and after treatment

\begin{tabular}{|l|c|c|c|}
\hline \multicolumn{1}{|c|}{ Time } & Before Treatment & After Treatment & p-value \\
\hline Blood pressure & $125 \pm 14$ & $122 \pm 12.3$ & 0.0 \\
\hline Diastolic $(\mathrm{mmHg})$ & $78.9 \pm 9.3$ & $78.3 \pm 7.6$ & 0.29 \\
\hline
\end{tabular}


Heart rate showed no statistically significant difference after treatment when compared to their values before treatment $(83.43 \pm 11.36$ vs $83.60 \pm 12.06$ beat/minute respectively). The $\mathbf{P R}$ interval showed no statistically significant difference after treatment when compared to their values before treatment $(143.85 \pm 16.83$ vs $142.23 \pm 17.67 \mathrm{msec}$ respectively). The QRS duration showed no statistically significant difference after treatment $(96.86 \pm 8.13 \mathrm{msec})$ when compared to their values before treatment $(97.09 \pm 7.80$ $\mathrm{m} / \mathrm{s}$ ). The QT interval showed no statistically significant difference after treatment when compared to their values before treatment $(357.97 \pm 26.35$ vs358.67 $\pm 26.42 \mathrm{msec}$ respectively) and corrected QT interval also showed no statistically significant difference after treatment $(422.10 \pm 18.81)$ when compared to their values before treatment (421.82 \pm 27.23$)$. No significant alterations regarding ST segment and $\mathbf{T}$ wave or arrhythmias between the start and the end of treatment course (Table 3).

Table (3): ECG parameters before and after treatment

\begin{tabular}{|l|l|l|l|}
\hline \multicolumn{1}{|c|}{ Time } & \multicolumn{1}{|c|}{ Before Treatment } & \multicolumn{1}{|c|}{ After Treatment } & p-value \\
\hline Rarameters $(\mathbf{b} / \mathbf{m})$ & $83.60 \pm 12.06$ & $83.43 \pm 11.36$ & 0.59 \\
\hline P-R interval (ms) & $142.23 \pm 17.67$ & $143.85 \pm 16.83$ & 0.44 \\
\hline QRS duration $(\mathbf{m s})$ & $97.09 \pm 7.8$ & $96.86 \pm 8.13$ & 0.79 \\
\hline QT $(\mathbf{m s})$ & $358.67 \pm 26.42$ & $357.97 \pm 26.35$ & 0.86 \\
\hline QTC & $421.82 \pm 27.23$ & $422.10 \pm 18.81$ & 0.38 \\
\hline
\end{tabular}

There was no statistically significant difference between any of echocardiography parameters before and after treatment. Only three measurements showed statistically significant difference;
LVESD mm (by 2D), IVSd mm (by 2D) and $\mathrm{EF}$ by $2 \mathrm{D} \%$ with p-values less than 0.05 , However, these differences were not clinically significant (Table 4). 
Table (4): Echo-Doppler parameters before and after treatment

\begin{tabular}{|l|l|l|l|}
\hline \multicolumn{1}{|c|}{ Time } & Before Treatment & After Treatment & p-value \\
\hline Parameters & $44.92 \pm 4.26$ & $45.82 \pm 4.68$ & 0.09 \\
\hline LVESD mm(by MM) & $29.18 \pm 3.08$ & $29.60 \pm 3.41$ & 0.16 \\
\hline IVSd mm(by MM) & $9.48 \pm 0.71$ & $9.44 \pm 0.76$ & 0.64 \\
\hline PWd mm(by MM) & $9.63 \pm 0.92$ & $9.54 \pm 0.94$ & 0.31 \\
\hline LA mm(by MM) & $33.47 \pm 3.81$ & $33.73 \pm 3.22$ & 0.46 \\
\hline AO mm(by MM) & $23.72 \pm 3.56$ & $23.69 \pm 3.5$ & 0.96 \\
\hline RVd mm(by MM) & $19.00 \pm 2.44$ & $19.37 \pm 2.36$ & 0.13 \\
\hline LVEDD mm(by 2D) & $42.29 \pm 5.1$ & $45.82 \pm 4.68$ & 0.09 \\
\hline LVESD mm(by 2D) & $27.53 \pm 3.58$ & $29.60 \pm 3.41$ & $0.0 *$ \\
\hline IVSd mm(by 2D) & $9.10 \pm 0.44$ & $9.35 \pm 0.67$ & $0.0 *$ \\
\hline PWd mm(by 2D) & $9.39 \pm 0.88$ & $9.44 \pm 0.79$ & 0.38 \\
\hline LVEDV cm3(by 2D) & $103.73 \pm 23.5$ & $102.42 \pm 25.1$ & 0.36 \\
\hline LVESV cm3(by 2D) & $40.82 \pm 11$ & $41.10 \pm 12.43$ & 0.92 \\
\hline EF by MM \% & $63.23 \pm 0.34$ & $62.73 \pm 3.17$ & 0.35 \\
\hline EF by 2D\% & $62.87 \pm 3.83$ & $64.25 \pm 3.2$ & $0.01 *$ \\
\hline EF by Simpson\% & $63.61 \pm 3.81$ & $63.59 \pm 3.51$ & 0.72 \\
\hline E/A & $2.21 \pm 8.56$ & $1.29 \pm 1.0$ & 0.15 \\
\hline e-(cm/s) & $10.36 \pm 2.67$ & $10.31 \pm 3.12$ & 0.61 \\
\hline E/e- & $8.25 \pm 2.31$ & $8.28 \pm 2.07$ & 0.78 \\
\hline IVRT(ms) & $86.86 \pm 15$ & $87.59 \pm 17$ & 0.79 \\
\hline DT(ms) & $161.62 \pm 43.57$ & $159.77 \pm 39$ & 0.65 \\
\hline RV MPI & $.16 \pm 0.1$ & $.15 \pm 0.09$ & 0.42 \\
\hline RV S-(mm) & $14.64 \pm 2.4$ & $14.86 \pm 2.52$ & 0.47 \\
\hline TAPSE(mm) & $24.33 \pm 4.5$ & $24.23 \pm 3.77$ & 1.00 \\
\hline PASP(mmHg) & $21.48 \pm 4.58$ & $21.50 \pm 4.87$ & 0.89 \\
\hline PVR(WU) & $1.53 \pm 0.33$ & $1.47 \pm 0.36$ & 0.17 \\
\hline
\end{tabular}

*Statistically significant difference.

2D=2-dimensional echocardiography, $\mathrm{AO}=$ aortic root, $\mathrm{EF}=$ ejection fraction, IVRT $=$ isovolumic relaxation time. $\mathrm{DT}=$ deceleration time, $\mathrm{IVSd}=$ interventricular septum in diastole, LA =left atrium, LVEDD =left ventricular end diastolic diameter, LVEDV=left ventricle end diastolic volume, $\mathrm{LVESD}=\mathrm{left}$ ventricular end systolic diameter, LVESV=left ventricle systolic volume,
Mm=millimeters, $\quad \mathrm{MM}=\quad$ M-mode, $\mathrm{mmHg}=$ millimeter of mercury, $\mathrm{PASP}=$ pulmonary artery systolic pressure, $\mathrm{PVR}=$ pulmonary vascular resistance, $\mathrm{PWd}$ $=$ posterior wall in diastole, RV MPI=right ventricle myocardial performance index, TAPSE=tricuspid annular plane systolic excursion, $\mathrm{RVd}=$ right ventricle in diastole, WU=wood units. 


\section{DISCUSSION}

Regarding the new DAAs, Food and Drug Administration (FDA) recently announced a change in labeling for the hepatitis $\mathrm{C}$ antiviral LDV/SOF (Harvoni) and SOF (Sovaldi) after the manufacturers reported bradycardia, pacemaker invention, and even death in patients who took the medications along with amiodarone (FDA hepatitis update, 2015).

As the prevalence of HCV in Egypt is high, and the new treatment combined with therapy involving oral DAAs either with or without PEG-IFN is extensively used.

The present study was designed to investigate the cardiovascular effect of DAAs on non-cardiac $\mathrm{HCV}$ patients. It included (100) Egyptian cases with HCV infection, who attended Luxor Insurance clinic for treatment by DAAs .

All included subjects were submitted to full history taking, clinical examination, laboratory investigations, twelve lead resting ECG, transthoracic Echo-Doppler study pre \& post antiviral course .

Several studies from different parts of the world have reported that $\mathrm{HCV}$ infection may also contribute to the development of diabetes mellitus (DM), and higher prevalence of type $2 \mathrm{DM}$ has been observed in patients with $\mathrm{HCV}$ infection than in those with other forms of chronic hepatitis (Bernsmeier \& Heim 2009, and Lonardo et al. 2009).

(Rouabhia et al., 2010) reported that the prevalence of diabetes in $\mathrm{HCV}$ Algerian patients was reported to be $39.1 \%$.
In the present work, the laboratory tests showed the fitness of the studied patients to receive DAAs therapy; unfortunately, no values at the end of the course of treatment were obtained. In the literature, it was reported that, DAAs resulted in suppression of baseline levels of hemoglobin, hematocrit, white blood cells, and pancytopenia.

In the present study, baseline clinical examination was done as regard determination of blood pressure, pulse, jugular venous pressure, pallor, jaundice, cyanosis, ascites, edema of the lower limbs, S3, S4 and any detected murmurs \&shortness of breath, cough, hemoptysis, palpitation and chest pain, paroxysmal nocturnal dyspnea and then reassessed by the end of treatment. No statistically significant difference was found between after treatment and baseline findings before treatment.

Wong. (2009) reported that, several electrophysiological abnormalities have been observed in cirrhosis and these include of chronotropic incompetence, electromechanical uncoupling, and prolonged QT interval .

These results are quite different that those reported in the present work, as it was reported with liver cirrhosis but in the present study the included patients are in early stages of hepatitis $\mathrm{C}$ infection with no evidence of cirrhosis. In addition, there was no data in the literature as regards the effect of DAAs QT and QTc.

Fontaine et al. (2015) reported three cases of severe bradyarrhythmia that occurred during treatment with Sofosbuvir plus Daclatasvir, Simeprevir, or ribavirin 
among 415 patients treated in their unit from January 2 to December 31, 2014.

But in the present study, there was no statistically significant difference was in rhythm found between after treatment and baseline findings before treatment .

Ahmad et al. (2015) Reported in their study on Thirty-four patients received Interferone-free BMS (Bristol-Myers Squibb) regimens (Sofosbuvir included regimen); Six patients had left ventricular ejection fractions (LVEFs) $<30 \%, 8$ had LVEFs 30\%-50\%, and 11 required hospitalization for suspected cardiotoxicity. Of the patients with LVEF $<50 \%$, 6 had normalization of systolic function after a median of 20 days. T-wave inversions were the most sensitive predictor of LVEF dysfunction. These results are quite different that those reported by Biomy et al. (2015) on their Study findings which showed no significant alterations in patient symptoms (shortness of breath, palpitations, and chest pain), signs (heart rate and blood pressure), or ECG recordings (arrhythmias, QT interval, or ST-T wave changes) before and after the oral antiviral treatment. In addition, there were no significant alterations in echocardiographic parameters regarding the systolic and diastolic functions before and after the oral antiviral treatment).

Also, these results are quite different that those reported in the present work ,Which indicate that DAAs therapy did not induce any significant change in left ventricular systolic and diastolic function, none of patients had or developed echocardiographic RWMA at the baseline or at the end of the study .Systolic function parameters showed non- significant changes over the study visits, Similarly, diastolic function parameters (E/A ratio, deceleration time, IVRT and E/e- ratio) showed no significant alterations between the beginning and at the follow-up visits .

In agreement with the results of this study, a review of the FDA Adverse Event Reporting System quarterly reports, on DAAs that are available in the market since 2011, showed no reported cases of serious cardiac complications caused by these novel therapies.

Renard et al. (2016) reported three cases of newly diagnosed or exacerbated severe pulmonary arterial hypertension (PAH) in patients treated with Sofosbuvir.

Our study results indicated that DAAs therapy did not induce any significant change in pulmonary artery pressure. This could be due to that PAH have been related to multiple associated factors besides DAA treatment.

\section{CONCLUSION}

The present findings suggested that this therapy seemed that it has no cardiovascular effects.

\section{This study has some limitations:}

- The small sample size of included cases.

- Incomplete follow up of DAAs therapy course .

- Follow up for the possible electrophysiological abnormalities were not used, e.g. Holter monitoring.

- Myocardial perfusion imaging for the detection of possible ischemia were not used. 


\section{REFERENCES}

1. Abbas A, Franey L, Marwick T, Maeder M, Kaye D, Vlahos A, Serra W, Al-Azizi K, Schiller N and Lester S. (2013): Noninvasive Assessment of Pulmonary Vascular Resistance by Doppler Echocardiography, 26(10):11701177.

2. Ahmad T, Yin P, Saffitz J, Pockros P, Lalezari J, Shiffman M, Freilich B, Zamparo $\mathrm{J}$, Brown $\mathrm{K}$, Dimitrova $\mathrm{D}$, Kumar $\mathrm{M}$, Manion D, Chiozzi M, Wolf R, Hughes E, Muir A and Hernandez1 A. (2015): Cardiac Dysfunction Associated With a Nucleotide Polymerase Inhibitor for Treatment of Hepatitis C. Hepatology, 62(2):409-16.

3. Bernsmeier $C$ and Heim M. (2009): Insulin resistance in chronic hepatitis $\mathrm{C}$ : mechanisms and clinical relevance. Swiss Medical Weekly, 139(47-48):678-684.

4. Biomy R, Abdelshafy M, Abdelmonem A, Abu-Elenin H and Ghaly G. (2017): Effect of Chronic Hepatitis C Virus Treatment by Combination Therapy on Cardiovascular System. Clin Med Insights Cardiol, 11: 1179546817713204.

5. Chak E, Talal A, Sherman K, Schiff $E$ and Saab S. (2011): HCV infection in USA an estimate of true prevalence, (8):1090-101.

6. FDA hepatitis update-important safety information. (2015): Harvoni and Sovaldi. USFDA /bulletins, f97c71.

7. Fontaine H, Duboc D and Pol S. (2015): Bradyarrhythmias Associated with Sofosbuvir Treatment. N Engl J Med., 373(19):1886-8.

8. Keating G. (2014): Sofosbuvir : a review of its use in patients with chronic hepatitis C. Drugs, 74(10):1127-46.

9. Lashen SA and Sanhoury MI. (2016): Syncope Following Sofosbuvir Therapy for Chronic Hepatitis C. Jounral of Liver Research, 2(4): 00032.

10. Lonardo A, Adinolfi L, Petta S, Crax?A and Loria P. (2009): Hepatitis $C$ and diabetes: the inevitable coincidence? Expert Rev Anti Infect Ther, (3):293-308.

11. Mitchell C, Rahko P, Blauwet L, Canaday $\mathbf{B}$, Finstuen J, Foster $\mathbf{M}$, Horton $\mathbf{K}$, Ogunyankin K, Palma R, and Velazquez E. (2018): Guidelines for Performing a Comprehensive Transthoracic Echocardiographic Examination in Adults: Recommendations from the American Society of Echocardiography.

12. Moyer V. (2013): Screening for hepatitis $C$ virus infection in adults: U.S. Preventive Services Task Force recommendation statement. Ann Intern Med., 159(5):349-57.

13. Pawlotasky J. (2014): New hepatitis C therapies the toolbox, strategies and challenge. Gastroenterology, 146(5):1176-92.

14. Renard S, Borentain P, Salaun E, Benhaourech S, Maille B, Darque A, Bregigeon S, Colson P, Laugier D, Gaubert, $R$ and Habib G. (2015): Severe Pulmonary Arterial Hypertension in Patients Treated for Hepatitis C with Sofosbuvir. Chest, 149(3): 6973.

15. Rouabhia $S$, Malek $R$, Bounecer $H$ and Dekaken M. (2010): Prevalence of type 2 diabetes in Algerian patients with hepatitis $\mathrm{C}$ virus infection. World J Gastroenterol.,16(27): 3427-343.

16. Rudski L, Lai W, Afilalo L, Hua L, Mark D, Solomon S, Louie E and Schiller N. (2010): Assessment of the Right Heart in Adults. J Am Soc Echocardiogr. 23:685-713.

17. Wong F. (2009): Cirrhotic cardiomyopathy. Hepatol Int., 3(1):294-304. 


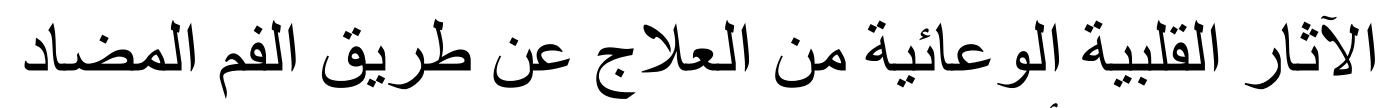

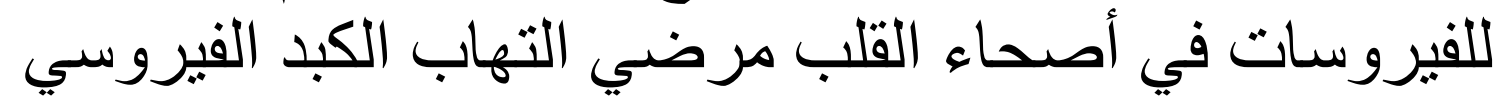
سبي

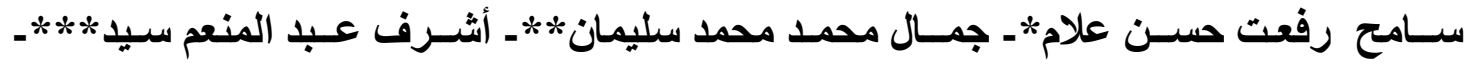
أحمد عبد الرؤوف مهذى" ـ محمود محمد أبو الحجاج"

*قسم القلب والأوعية الاموية **الأمراض المتوطنة ***:الباثولوجيا الإكلينيكية

كلية الطب جامعة الأزهر

خلفية البحث : إنتشار فيروس الالتهاب الكبدي الوبائي (سي) في مصر مرتفع ، وقد تكون نتائج العلاج عن طريق الفم المضاد للفيروسات مثيرة للاعجاب.

الهدف من البحث: تقييم الآثار القلبية الوعائية للعلاج عن طريق الفم في أصحاء القلب المرضى

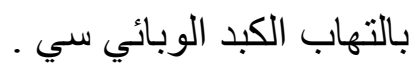

المرضي وطرق البحث: النحق بالدراسة ( . [ () مريض مصاب بفيروس إلتهاب الكبد الوبائي سي

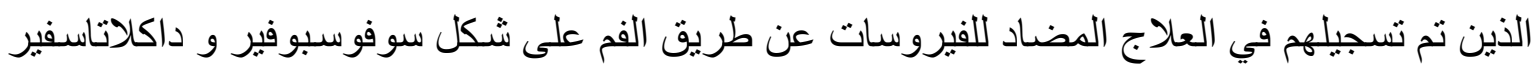

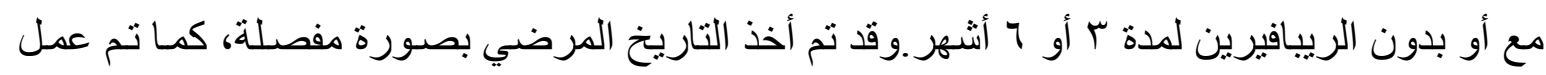

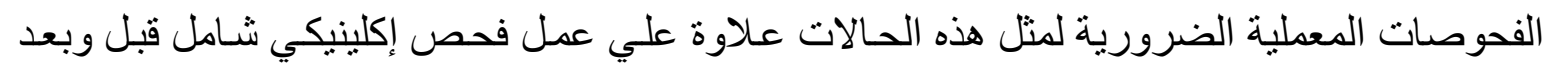
تناول العلاج كنلك تم عمل رسم قلب و الفحص بالموجات فوق الصوتية علي القلب قبل وبعد العلاج.

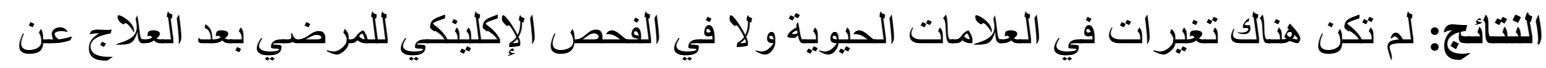

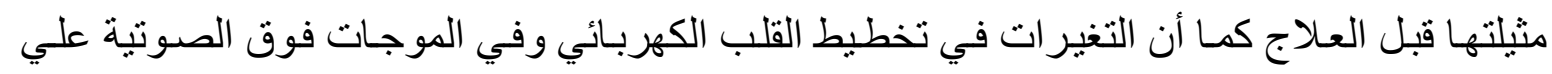
القلب كانت غير دالة إحصائيا بعد العلاج مقارنة بمثيلتها قبل العلاج.

الاستتناج: نتائج الدراسة الحالية تثير إلى أن العلاج عن طريق الفم المضاد للفيروس (سي) لا يوجد لايه تأثير ات على القلب والأو عية الدموية. 